\title{
Evapotranspiração máxima da cultura de pimentão em estufa plástica em função da radiação solar, da temperatura, da umidade relativa e do déficit de saturação do ar
}

\author{
Maximum evapotranspiration of sweet pepper in plastic greenhouse as a function of solar radiation, \\ temperature, relative humidity and water vapor pressure deficit of the air
}

\author{
Genei Antonio Dalmago ${ }^{1}$ Arno Bernardo Heldwein ${ }^{2}$ Astor Henrique Nied ${ }^{3}$ \\ Edenir Luis Grimm ${ }^{4}$ Carina Rejane Pivetta ${ }^{5}$
}

\section{RESUMO}

Um experimento foi conduzido para avaliar a relação da evapotranspiração máxima (ETm) da cultura de pimentão por unidade de índice de área foliar (ETmf) com a radiação solar global incidente $\left(R g_{e}\right)$ e saldo de radiação $\left(R n_{e}\right)$, externos à estufa, e com a temperatura $\left(t_{a m}\right)$, umidade relativa (URm) e déficit de saturação (D) do ar no interior da estufa. A ETm foi determinada por lisimetria. Apenas a temperatura e a umidade relativa do ar foram registradas e as demais variáveis foram estimadas. O Rn apresentou o maior efeito isolado, seguido pelo $D e$ pela URm. A temperatura do ar às 15 horas e a temperatura máxima diária foram as variáveis pontuais de maior associação com a ETmf. A $\mathrm{Rg}$ e melhorou sua relação quando analisada em diferentes faixas de $t_{\text {m. }}$. Os resultados confirmaram o $R n_{e}$ e o $\mathrm{D}$ como as variáveis meteorológicas de maior efeito preditivo da evapotranspiração das culturas em estufas plásticas no outono, porém com graus diferenciados de ajuste para o pimentão em relação às outras culturas.

Palavras-chave: consumo de água, Capsicum annuum, cultivos protegidos, elementos meteorológicos.

\section{ABSTRACT}

An experiment was carried out to study the relationship between sweet pepper maximum evapotranspiration (ETm) per unit leaf area index (ETmf) and incident solar radiation $\left(R g_{e}\right)$ and net radiation $\left(R n_{e}\right)$ outside greenhouse, and with air temperature $(t)$, air relative humidity $(U R m)$ and water vapor pressure deficit $(D)$ inside a greenhouse.
ETm was measured by lysimeters. Temperature and relative humidity were registered whereas $\mathrm{Rg}_{e}$ and $\mathrm{Rn} n_{e}$ were estimated. The $R n_{e}$ was the variable with largest effect on ETmf determination, followed by $D$ and URm. The air temperature at 15:00 and the daily maximum temperature were variables of larger association with ETmf among the variables with punctual time observations. $\mathrm{Rg}_{e}$ improved its relationship with ETmf when was analyzed with different $t_{a m}$ ranges. The results confirmed $R n_{e}$ and $D$ as the meteorological variables of highest relationship with evapotranspiration in plastic greenhouse grown crops in autumn. However, the degree of adjustment of this relationship for sweet pepper is different from those reported for other crops.

Key words: water consumption, Capsicum annuum, greenhouse, meteorological variables.

\section{INTRODUÇÃO}

Atendida a suplementação de água às plantas, na qualidade e na quantidade que necessitam para o consumo, o fluxo transpiratório é determinado basicamente pela área foliar e pela variação dos elementos meteorológicos que caracterizam a demanda hídrica. Na escala diária, o aumento da área foliar é relativamente pequeno. Nessa condição, as variáveis meteorológicas assumem maior importância na definição da evapotranspiração máxima (ETm) e comandam o transporte de água no sistema solo-plantaatmosfera.

\footnotetext{
${ }^{1}$ Programa de Pós-graduação em Fitotecnia, Universidade Federal do Rio Grande do Sul (UFRGS), Porto Alegre, RS, Brasil. E-mail: gdalmago@yahoo.com.br.

${ }^{2}$ Departamento de Fitotecnia, Universidade Federal de Santa Maria (UFSM), 97105-900, Santa Maria, RS, Brasil. E-mail: heldwein@ccr.ufsm.br.

${ }^{3}$ Programa de Pós-graduação em Agronomia da UFSM, Santa Maria, RS, Brasil.

${ }^{4}$ Programa de Pós-graduação em Engenharia Agrícola da UFSM, Santa Maria, RS, Brasil. E-mail: edenirgrimm@yahoo.com.br.

${ }^{5}$ Curso de Agronomia da UFSM, Santa Maria, RS, Brasil. E-mail: crpivetta@bol.com.br.
} 
No ambiente natural, as relações da ETm com as variáveis meteorológicas são bastante conhecidas para várias espécies. A transferência destes resultados para o interior de estufas não é adequada, pois, nesses locais os elementos meteorológicos são modificados principalmente pela presença da cobertura plástica, pelo manejo das aberturas de ventilação natural e pelo efeito da cultura. Em consequiência disso, o padrão de variação da ETm se modifica em relação ao ambiente externo numa dada condição meteorológica. Por isso, a determinação dessas relações para condição de estufa se faz necessária.

A radiação solar é o elemento meteorológico que mais afeta a ETm das culturas em ambientes protegidos (YANG et al., 1989; NERDERHOFF et al., 1992; STANGHELLINI, 1993), porque fornece a energia para esse processo. Porém, em altos níveis, pode induzir o fechamento estomático, reduzindo a transpiração, devido à elevação do déficit de saturação do ar no interior da estufa (BAILLE et al., 1994), o qual é modificado também pela abertura e fechamento da estufa. O efeito da radiação, segundo De VILLELE (1972), é linear e positivo devido à influência que a radiação exerce sobre o controle estomático (MARCELIS, 1989), enquanto não forem alcançados níveis altos o suficiente para causar estresse hídrico nas folhas mais expostas à radiação (BAILLE et al., 1994).

O déficit de saturação do ar na estufa também influencia significativamente a transpiração das plantas (OKUYA \& OKUYA, 1988; RIGHI, 2000). Os momentos de sombreamento durante o dia são o principal fator condicionante da ETm devido ao aumento da resistência estomática em conseqüência da redução da radiação solar incidente (FYNN et al., 1993). O déficit de saturação expressa uma aproximação do gradiente de pressão de vapor entre os sítios de transpiração e o ar ao seu redor, podendo ser considerado a força motriz do processo de transpiração (BOULARD et al., 1991).

A menos que um estresse de água cause suficiente fechamento estomático, o aumento da temperatura do ar geralmente eleva a transpiração das plantas na estufa pelo efeito sobre o déficit de saturação (STANGHELLINI, 1993). Para o tomateiro, VALANDRO et al. (1999) encontraram efeito diferenciado da temperatura do ar em diferentes períodos de cultivo $\left(\mathrm{r}^{2}\right.$ de 0,26 a 0,73), enquanto JOLLIET \& BAILEY (1992) não encontraram relação significativa entre temperatura do ar e transpiração das plantas. Esses resultados concordam, em parte, com a afirmação de BAILLE et al. (1992) de que a temperatura do ar isolada não é um indicador preciso da demanda de água das plantas no interior de estufas.
O aumento da umidade relativa do ar diminui a transpiração das plantas devido à diminuição do gradiente de concentração de vapor entre a cavidade estomática e o ar adjacente à folha, mediada pela redução do déficit de saturação de vapor do ar (VALANDRO et al., 1999; RIGHI, 2000). O aumento da resistência ou o fechamento estomático podem ocorrer também, com baixos níveis de umidade relativa do ar, o que reduziria ainda mais a relação com a ETm (BAILLE et al., 1994).

O entendimento dessas relações é importante para melhorar o manejo das culturas e agregar qualidade ao produto final. A importância desses estudos na cultura de pimentão se justifica pelo fato de que outras espécies mostraram variações diferenciadas nas respostas à demanda hídrica, modulada pelos elementos meteorológicos. Por isso, o objetivo desse trabalho foi avaliar a relação da ETm por unidade de índice de área foliar com a radiação solar global incidente e o saldo de radiação externo à estufa, bem como com a temperatura e com a umidade relativa, além do déficit de saturação do ar no interior da estufa.

\section{MATERIAL E MÉTODOS}

O trabalho foi desenvolvido no período de 15/02 à 02/06/2000, numa estufa plástica localizada no Departamento de Fitotecnia da Universidade Federal de Santa Maria (latitude: $29^{\circ} 43^{\prime} 23^{\prime \prime}$, longitude: $53^{\circ}$ 43'15”W e altitude: 95m). O clima da região, segundo a classificação de Köppen, é do tipo Cfa, subtropical úmido com verões quentes (MORENO, 1961).

A estufa plástica possuía $24 \mathrm{~m}$ de comprimento (Norte-Sul) e 10m de largura, com altura de $3 \mathrm{~m}$ na parte central e $2 \mathrm{~m}$ de pé-direito. A cobertura em formato de arco foi recoberta com filme plástico transparente de polietileno de baixa densidade (PEBD), de $100 \mu$ de espessura. As laterais (fixas até um metro acima do nível do solo) e as cortinas móveis (acima deste nível), bem como as portas e as extremidades Norte e Sul foram fechadas com o PEBD. O manejo das cortinas e portas para a ventilação foi realizado conforme a condição meteorológica do dia (HELDWEIN et al., 2001).

As plântulas de pimentão, Capsicum annuum L., híbrido Vidi F1, foram transplantadas em camalhões recobertos com "mulching" de filme opaco de PEBD preto, com perfurações de 0,06 m de diâmetro em torno das plantas. $\mathrm{O}$ espaçamento foi de $0,30 \mathrm{~m}$ entre plantas e de 1 metro entre fileiras $\left(0,30 \mathrm{~m}^{2}\right.$ planta $\left.^{-1}\right)$, e as plantas foram conduzidas em haste única. A 
irrigação foi realizada por gotejamento e a quantidade controlada por tensiometria (DALMAGO et al., 2001).

A ETm foi determinada por lisimetria, utilizando-se dois tipos de lisímetros de drenagem cobertos com "mulching” perfurado em torno das plantas, da mesma forma que nos camalhões do solo da área de bordadura, num total de 11 repetições (DALMAGO et al., 2001). Autilização dos lisímetros de barragem baseou-se na elevada relação que a ETm apresentou entre eles (DALMAGO et al., 2001), aumentando assim a representatividade para compensar o sombreamento temporário de cada um causado pela estrutura de sustentação da cobertura em diferentes momentos do dia.

O índice de área foliar ( $I A F)$ foi determinado, em intervalos de sete dias, a partir da área de cada folha $\left(A F ; \mathrm{cm}^{2}\right)$, estimada pela equação $A F=0,464328 C^{1,837927}$ (DALMAGO, 2001), em função do seu comprimento $(C ; \mathrm{cm})$, para a cultura de pimentão em estufa plástica. Os valores diários de IAF foram obtidos por interpolação, pelo ajuste de equações em função dos dias após o transplante (DAT).

Os detalhes do manejo da cultura de pimentão, a determinação e o procedimento de cálculo da ETm e os detalhes do cálculo do IAF são descritos em DALMAGO (2001) e DALMAGO et al. (2001).

A densidade de fluxo de radiação solar global no exterior da estufa $\left[R g_{e},\left(\mathrm{MJ} \mathrm{m}^{-2} \mathrm{dia}^{-1}\right)\right]$ foi estimada a partir dos dados de insolação registrados na estação meteorológica, através da equação de Ångströn-Prescott, com os coeficientes mensais ajustados para Santa Maria (ESTEFANEL et al., 1990). $\mathrm{O}$ saldo de radiação externo $\left[R n_{e},\left(\mathrm{MJ} \mathrm{m}^{-2} \mathrm{dia}^{-1}\right)\right]$ foi calculado pela equação de Brunt-Penman (BERLATO \& MOLION, 1981). No interior da estufa, registrou-se continuamente a temperatura e a umidade relativa do ar com termohigrógrafo instalado a 1,5 m acima do solo, dentro do abrigo meteorológico. Os valores médios da temperatura $\left[t_{a m},\left({ }^{\circ} \mathrm{C}\right)\right]$, umidade relativa $[U R m,(\%)]$ e o déficit de saturação do ar $[D,(\mathrm{hPa})]$ foram determinados a partir de 12 valores cotados dos termohigrogramas, a intervalos de duas horas. Os valores de $D$ foram calculados pela diferença entre a pressão de saturação (e ) e a pressão parcial de vapor ( $e$ ) a partir dos valores de temperatura e umidade relativa do ar. Calcularam-se também a temperatura $\left[t_{\text {amd }}\left({ }^{\circ} \mathrm{C}\right)\right]$, a umidade relativa $\left[U R m_{d},(\%)\right]$ e o déficit de saturação do ar médio $\left[D_{d}\right.$, (hPa)] no interior da estufa para o período diurno, compreendido entre $6 \mathrm{~h}$ e $18 \mathrm{~h}$.

Para isolar o efeito das variáveis meteorológicas e analisar os dados numa mesma base referencial, a ETm foi dividida pelo $I A F$, constituindose na evapotranspiração máxima por unidade de índice de área foliar (ETmf). Utilizaram-se os dados a partir da segunda semana após o transplante, momento em que as plantas estavam estabelecidas. Os dias 76, 77 e 78 após o transplante foram excluídos devido a erros na determinação da $E T m$. A separação dos dados em três classes de temperatura do ar interna $\left(<15^{\circ} \mathrm{C}, 15^{\circ} \mathrm{C}\right.$ a $20^{\circ} \mathrm{C}, \geq 20^{\circ} \mathrm{C}$ ) foi baseada em RIGHI (2000).

\section{RESULTADOS E DISCUSSÃO}

O $R n$ foi a variável que melhor representou o efeito da radiação solar na ETmf da cultura de pimentão (Figura 1a), com relação linear positiva próxima àquela obtida por NERDERHOFF et al. (1992) para a mesma cultura, porém em condição climática diferente $\left(r^{2}=0,91\right)$. Para a maioria das espécies cultivadas em ambientes protegidos na Europa, essa relação tem sido estabelecida com a $R g$ (ANDRIOLLO, 1999). No presente caso, o ajuste com a $R g_{e}$ foi inferior àquele com o $R n_{e}$ (Figura 1b). HELDWEIN et al. (2004), trabalhando com abóbora italiana e metodologia similar,
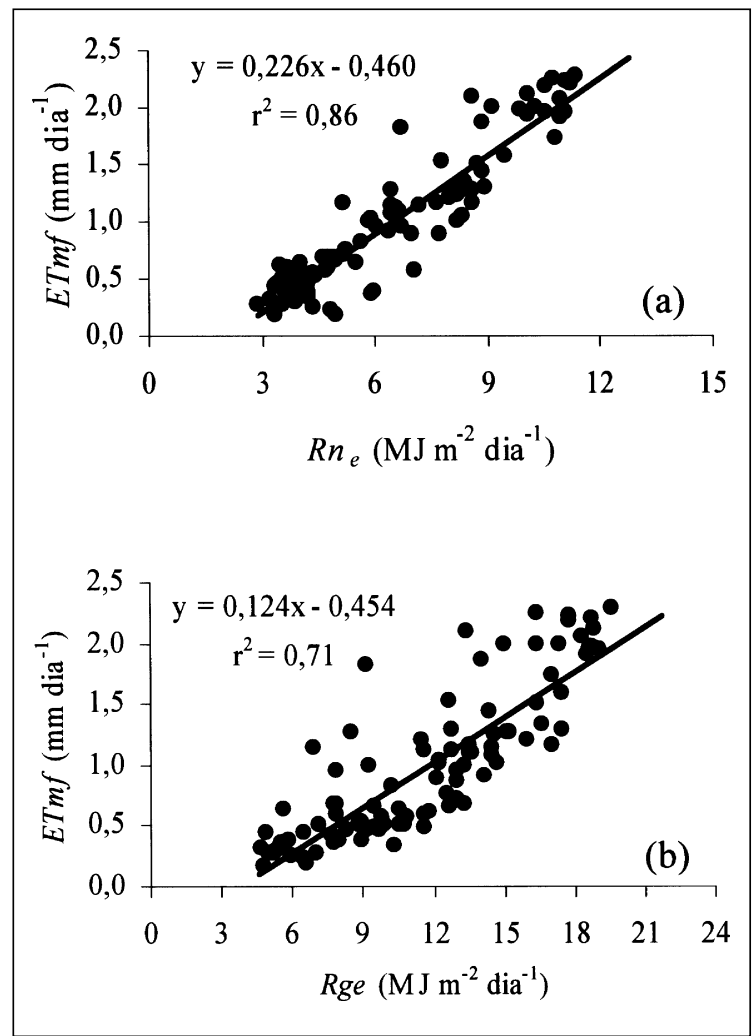

Figura 1 - Evapotranspiração máxima diária da cultura de pimentão por unidade de índice de área foliar (ETmf), em estufa plástica, em função do saldo de radiação diário $\left(R n_{e}\right)$ (a) e da radiação solar global diária $\left(R g_{e}\right)$ (b) no ambiente externo à estufa plástica. Santa Maria, RS - 2001

Ciência Rural, v.36, n3, mai-jun, 2006. 
também verificaram melhor relação da $E T m f$ com $R n$ do que com $R g_{e}$. Para as duas variáveis, o ajuste då função polinomial quadrática não foi significativo, confirmando a relação linear apresentada por De VILLELE(1972).

A tendência observada na figura $1 \mathrm{a}$ e $1 \mathrm{~b}$ provavelmente ocorreu porque o aquecimento das folhas decorrente da absorção da radiação solar aumenta a diferença de pressão de vapor d’água entre o dossel das plantas e o meio, que é similar ao déficit de saturação de vapor entre as folhas e o ar adjacente, enquanto que a abertura estomática reduz a resistência ao fluxo de vapor. Esses dois fatores combinam com a forte associação da radiação solar com a temperatura e umidade relativa do ar no interior da estufa, resultando na tendência linear esperada (STANGHELLINI, 1993).

A relação linear entre $R g_{e}$ e ETmf apresentou coeficiente de determinação de apenas 0,71 e a quadrática 0,74. Essa relação, no entanto, melhorou significativamente quando a associação foi realizada para as três classes de $t_{a m}$ (Figura 2). Na faixa de $t_{a m}<$ $15^{\circ} \mathrm{C}$, o ajuste se aproximou daquele obtido com o $R n_{e}$ (Figura 1a). Para as demais classes, a melhora do $\mathrm{r}^{2}$ foi menor, porém significativa, na medida em que a temperatura foi mais elevada (Figura 2). Na classe das $t_{a m} \geq 20^{\circ} \mathrm{C}$, a maior dispersão dos pontos, principalmente nos dias de alta $R g_{e}$, poderia estar indicando aumento da resistência estomática e conseqüente redução da transpiração nos momentos de elevada incidência de radiação solar, quando associada a elevados níveis de déficit de saturação, conforme mostrado por BAILLE et al. (1994) para a cultura de roseiras. Nos dias com $t_{a m}$ $\geq 20^{\circ} \mathrm{C}$, a possibilidade de ocorrer defasagem entre a perda e a absorção de água pelas plantas aumenta. Esta condição, associada às diferentes combinações possíveis entre a radiação solar e o déficit de saturação do ar, pode aumentar a resistência estomática mesmo em plantas bem irrigadas, como o que ocorre no chamado déficit de curto prazo. Portanto, é esperado que a dispersão dos valores de ETmf aumente quando as condições que determinam a evapotranspiração se encontram no seu extremo superior, uma vez que as associações estabelecidas entre as variáveis podem mudar de magnitude por uma pequena mudança de uma ou de outra variável associada ao processo de transpiração. Isso é salientado pela defasagem entre a absorção e a perda de água em momentos de elevada demanda evaporativa do ar, ou seja, quando ocorreram os maiores valores de ETmf.

A modificação do ajuste em função das diferentes faixas de temperatura observada na figura 2 se deve, principalmente, ao manejo de abertura e fechamento da estufa. O manejo piora a relação entre $R g_{e}$ e ETmf, pois altera a associação entre radiação solar e temperatura do ar. Isso porque, nos dias frios ou chuvosos, de baixa radiação solar, a estufa permaneceu fechada por mais tempo. Embora o fechamento da estufa eleve a temperatura em seu

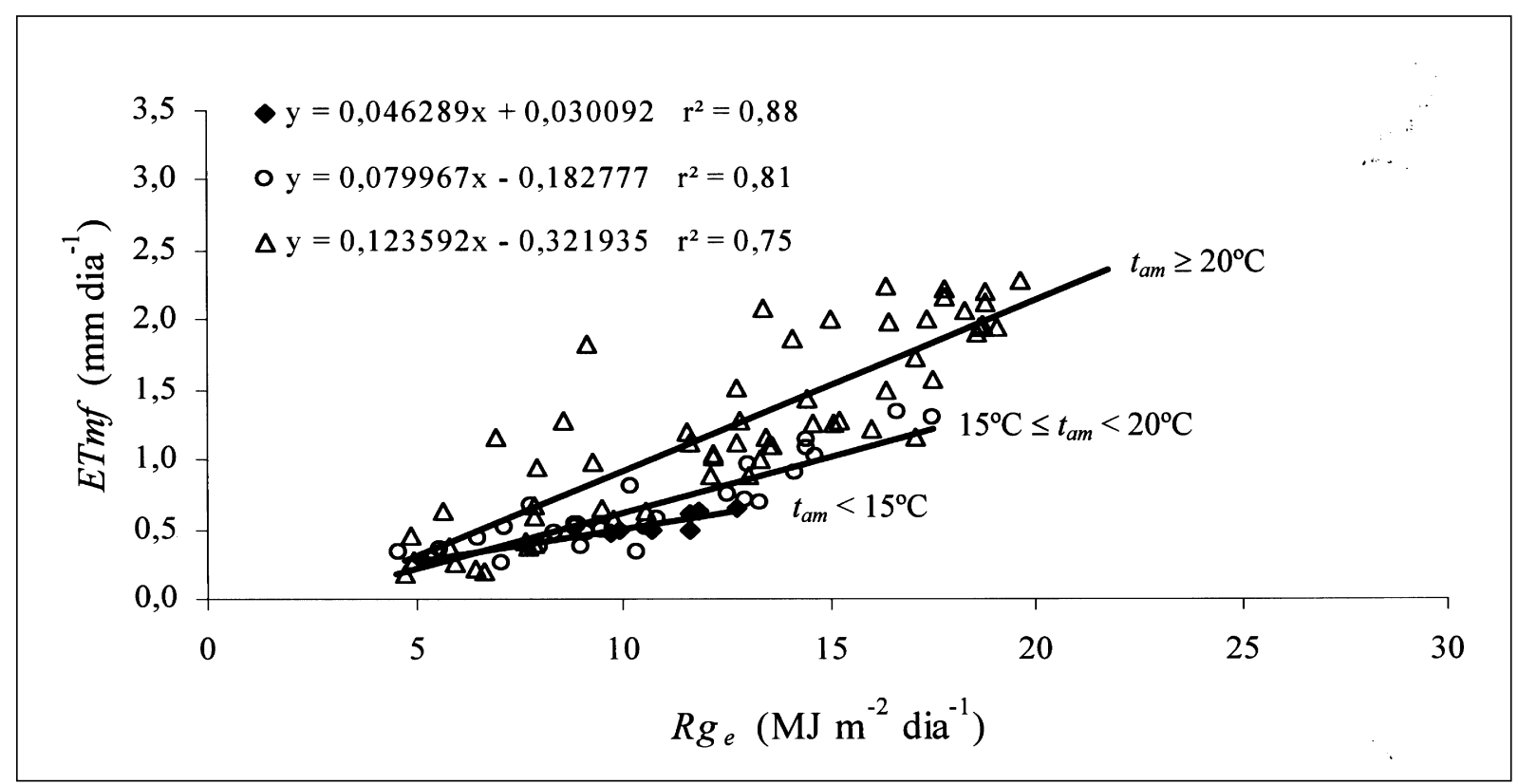

Figura 2 - Evapotranspiração máxima diária da cultura do pimentão por unidade de índice de área foliar (ETmf) em função da densidade de fluxo de radiação solar global diária externa à estufa $\left(R g_{e}\right)$ para diferentes intervalos de temperatura média diária do ar no interior da estufa $\left(t_{a m}\right)$. Santa Maria, RS - 2001. 
interior, em dias mais frios a ETmf para um mesmo nível de $R g_{e}$ em geral é menor, devido à diminuição do déficit de saturação do ar no interior da estufa e conseqüente diminuição da radiação solar transmitida pela cobertura, em função da condensação na face interna do filme plástico. Portanto, nessa condição, a $R g_{e}$ integralizou indiretamente o efeito do $D$ na ETmf dos intervalos de $t_{a m}\left(R g_{e}\right.$ versus $D, \mathrm{r}^{2}=0,71 ; 0,77$ e 0,65 para $t_{a m}<15^{\circ} \mathrm{C}$, $15^{\circ} \mathrm{C} \leq t_{a m}<20^{\circ} \mathrm{C}$ e $t_{a m} \geq 20^{\circ} \mathrm{C}$, respectivamente), sendo que o menor $\mathrm{r}^{2}$ entre $R g_{e}$ e $D$ para $t_{a m} \geq 20^{\circ} \mathrm{C}$ poderia ser conseqüência do fechamento parcial dos estômatos sob condições de elevada demanda hídrica.

A influência da $t_{a m}$ (Figura 3a) foi menor do que a da $R g_{e}$, provavelmente porque o cálculo da $t_{a m}$ englobou todo o período diário, enquanto a ETmf ocorreu praticamente apenas na presença da radiação solar. No entanto, houve associação, embora com um $\mathrm{r}^{2}$ de apenas 0,45 , ao contrário do que afirmaram JOLLIET \& BAILEY (1992) para o tomateiro, e a ETmf manteve a tendência de aumento com a elevação da $t_{a m}$ (STANGHELLINI, 1993). Porém, o baixo $\mathrm{r}^{2}$ ratifica a afirmação de BAILLE et al. (1994) de que a $t_{a m}$ isolada não é um indicador preciso da demanda de água das plantas no interior das estufas.

A utilização da $t_{a m d}$ elevou o r $^{2}(0,53)$, o que também ocorreu com a temperatura do ar das 15 horas $\left(t_{a 15}\right)\left(\mathrm{r}^{2}=0,60\right)$ e temperatura máxima do ar $\left(t_{\text {máx }}\right)$ $\left(\mathrm{r}^{2}=0,51\right)$. A melhora no ajuste, com esses três dados de temperatura, pode ser explicado talvez pelo efeito das mesmas no $D$ e na resistência estomática. Enquanto $t$ versus $D$ resultou em $\mathrm{r}^{2}=0,59$, a relação entre $t_{a m d}$ e $D$, entre $t_{a 15}$ e $D$, e entre $t_{\text {máx }}$ e $D$, apresentou $\mathrm{r}^{2}$ de $0,66,0,73$ e 0,76 , respectivamente. Como essas temperaturas geralmente são mais elevadas do que a $t_{a m}$, a resistência estomática é menor nesses períodos, uma vez que a mesma tende a diminuir com o aumento da temperatura do ar, embora só até um determinado nível (RIGHI, 2000), provavelmente por estresse térmico.

Embora possa existir a idéia da alta relação da radiação solar média com a temperatura do ar das 15 horas e da relação também elevada com a evapotranspiração, como explicar então a melhora no ajuste da ETm, com a temperatura às 15 horas em relação à temperatura média, uma vez que a temperatura média também tem forte relação com a radiação solar? Considerando que o déficit de saturação é uma variável com forte influência na determinação da ETm, e tem relação exponencial com a temperatura do ar, é esperado que o déficit de saturação tenha mais influência como variável preditora da ETmf. Além disso, deve ser considerado que, depois de atendida a quantidade de radiação solar necessária para a abertura estomática, é a temperatura do ar a variável que pode influenciar de forma mais significativa o aumento ou a redução da resistência estomática.

O melhor ajuste da $U R m$, (Figura 3b) em relação a $t_{a m}$, pode ser atribuído ao fato de que a $U R m$ apresenta um efeito interativo com a transpiração em meio à cultura, pois a transpiração é a principal fonte de vapor d'água no interior da estufa (BAILLE et al., 1994). A ETmf pode ser diminuída quando a $U R m$ é reduzida ao ponto de causar redução da abertura estomática (BAILLE et al., 1994), condição que provavelmente não ocorreu na grande maioria dos dias (Figura 3b).

Da mesma forma que para a $t_{a m}$, foram avaliadas as relações da $U R m_{d}$, da umidade relativa mínima diária $\left(U R_{\text {min }}\right)$ e da umidade relativa das 15 horas $\left(U R_{15}\right)$ com a ETmf, obtendo-se ${ }^{2}$ de 0,67, 0,41 e 0,40, respectivamente. A redução do ajuste com a $U R_{\text {min }} \mathrm{e}$ $U R_{15}$, deve-se às dificuldades de cotação dos seus valores do termohigrograma, os quais, nesses horários, normalmente apresentam grandes oscilações no registro, condição que não ocorre com a $t_{a m}$. A menor associação entre as variáveis $E T m f$ e $U R_{15}$ e $U R_{m}$ provavelmente também foi devida às variáveis $U R$ e $U R_{\min }$ resultarem de leituras pontuais e, portanto, êm muitos dias poderiam não representar as condições de demanda ocorridas em todo o período diário, representando com menor precisão a ETmf ao longo deste período. Por outro lado, a semelhança no ajuste entre a $U R m$ e a $U R m_{d}$ pode ser devida a essas variáveis integrarem os valores de umidade relativa ocorridos quando a estufa foi mantida fechada, no período diurno (RIGHI, 2000), bem como à associação que essas variáveis apresentaram com os respectivos valores de $D\left(\mathrm{r}^{2}=0,83\right.$ e 0,85$)$.

O ajuste do $D$ com a ETmf (Figura 3c) apresentou tendência linear semelhante àquela verificada com a radiação solar (Figuras 1a e 1b), pelo menos para $D<11$, o que pode ser atribuído ao fato da radiação solar integrar, em parte, o efeito do $D$ na determinação da ETmf, principalmente durante períodos de sombreamento (FYNN et al., 1993). A semelhança nas relações da $E T m f$ com a radiação solar e o $D$, no interior da estufa mostra que o $D$ interno foi dependente do $R n_{e}\left(\mathrm{r}^{2}=0,78\right)$. A variável $D$ varia exponencialmente em função da oscilação da $t_{a m}$ no interior da estufa, a qual, por sua vez, modifica-se em função da radiação $\operatorname{solar}\left(R n_{e}, \mathrm{r}^{2}=0,54\right)$. Dessa maneira, pode ser esperado que o saldo de radiação apresente uma associação muito semelhante àquela do $D$ ou, pelo menos, mantenha a mesma tendência. No entanto, existem casos em que o fluxo de radiação é elevado e o $D$ interior é baixo, reduzindo a ETmf, como o que ocorreu em dias 


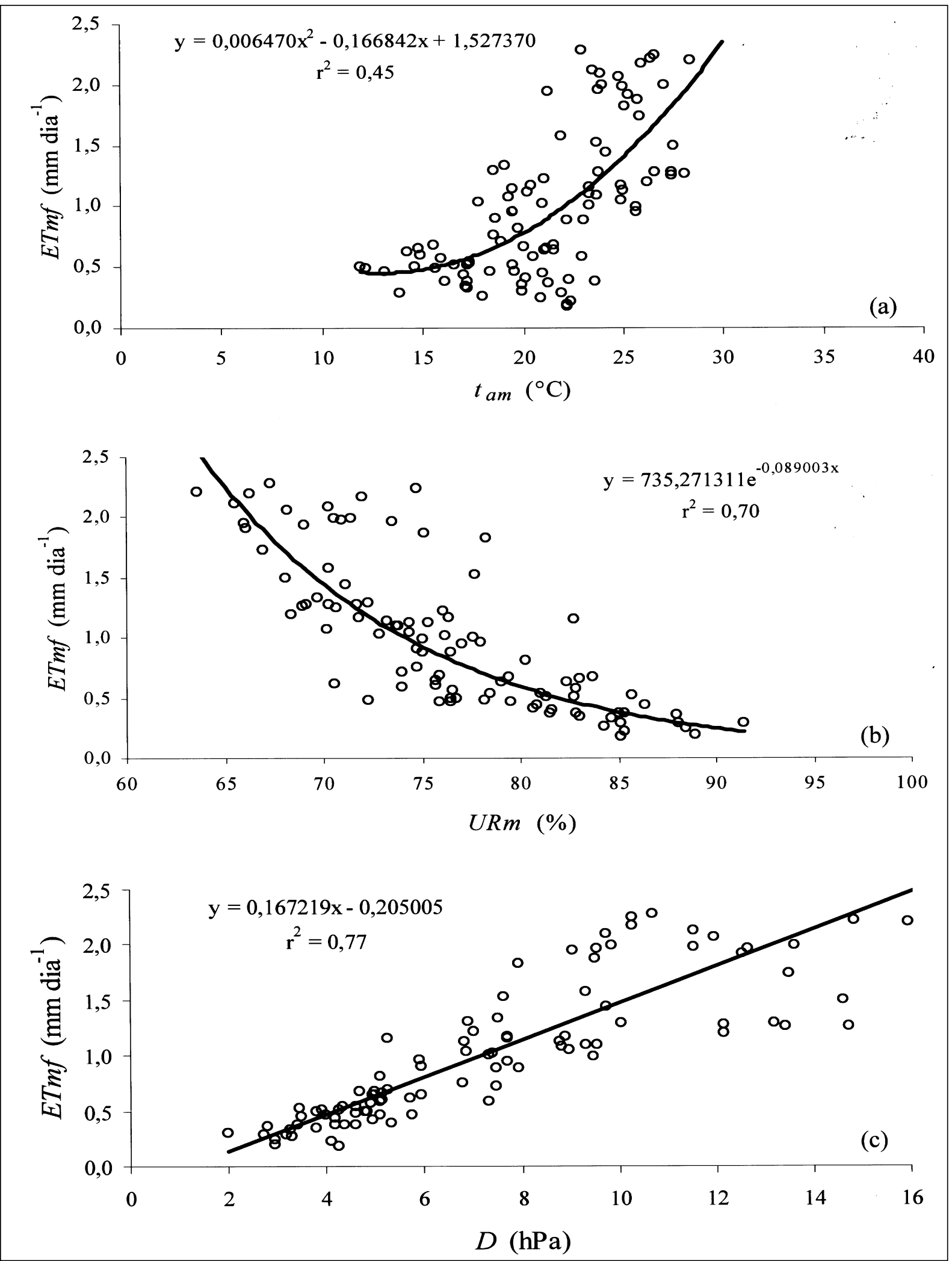

Figùra 3 - Evapotranspiração máxima diária da cultura de pimentão por unidade de índice de área foliar (ETmf) em função da temperatura média diária do ar $\left(t_{a m}\right)(a)$, da umidade relativa do ar média diária $(U R m)$ (b) e do déficit de saturação do ar médio diário (D) ( c) no interior da estufa . Santa Maria, RS - 2001.

Ciência Rural, v.36, n.3, mai-jun, 2006. 
em que a estufa permaneceu fechada. Pode-se, também, esperar o contrário, isto é, baixa incidência de radiação e elevado $D$ interno, conseqüência do armazenamento de energia em dias anteriores, o que aumentaria a ETmf. Essa relação ainda pode ser modificada pelo manejo de abertura e fechamento das laterais da estufa, que interfere em todos esses processos. Porém, é provável que o saldo de radiação solar e o déficit de saturação do ar se mantenham como as variáveis meteorológicas que mais condicionam a evapotranspiração do pimentão no outono. Valores de $D$ maiores do que 11 tenderam a não aumentar a ETmf (Figura 3c), provavelmente devido a uma possível restrição hídrica nas horas mais quentes dos dias em que houve alta demanda atmosférica.

\section{CONCLUSÃO}

O saldo de radiação externo e o déficit de saturação do ar médio no interior da estufa são as variáveis meteorológicas que apresentam maior relação com a evapotranspiração máxima da cultura de pimentão em ambientes protegidos, no outono. A temperatura do ar interna apresenta relação mais acentuada com a evapotranspiração nos valores pontuais de temperatura máxima e nos das 15:00 horas, enquanto que a umidade relativa média diária e/ou umidade média diurna da estufa apresentam melhor associação com a evapotranspiração da cultura de pimentão do que seus valores pontuais.

\section{AGRADECIMENTOS}

Ao Conselho Nacional de Desenvolvimento Científico e Tecnológico (CNPq), pelas bolsas de Pós-doutorado, de Pesquisa e de iniciação científica concedidas ao primeiro, segundo e quinto autores, respectivamente, e à Coordenação de Aperfeiçoamento de Pessoal de Nível Superior (CAPES), pelas bolsas de mestrado concedidas ao terceiro e ao quarto autor.

\section{REFERÊNCIAS}

ANDRIOLO, J.L. Fisiologia das culturas protegidas. Santa Maria: UFSM, 1999. 142p.

BAILLE, M. et al. Microclimate and transpiration of greenhouse rose crops. Agricultural and Forest Meteorology, Amsterdam, v.71, p.83-97, 1994.

BAILLE, M. et al. Some comparative results on evapotranspiration of greenhouse ornamental crops, using lysimeter, greenhouse $\mathrm{H}_{2} \mathrm{O}$ balance and LVDT sensors. Acta Horticulturae, Wageningen, v.304, p.199-208, 1992.

BERLATO, M.A.; MOLION, L.C.B. Evaporação e evapotranspiração. Porto Alegre: IPAGRO, 1981. 96p. (Boletim Técnico, 7).
BOULARD, T. et al. Étude de différentes méthodes de refroidissemente su le climat et la transpiration de tomates de serre. Agronomie, Paris, v.11, p.543-553, 1991.

DALMAGO, G.A. Evapotranspiração máxima e sua modelagem para a cultura do pimentão em estufa plástica. 2001. 166f. Dissertação (Mestrado em Agronomia) - Programa de Pós-graduação em Agronomia, Universidade Federal de Santa Maria.

DALMAGO, G.A. et al. Avaliação de métodos de determinação da evapotranspiração máxima da cultura de pimentão em estufa plástica. Revista Brasileira de Agrometeorologia, Santa Maria, v.9, n.2, p.201-211, 2001.

DE VILLELE, O. Besoins en eau des cultures sous serre: essai de conduite des arrosagesen function de l'ensoleillement. Acta Horticulturae, Wageningen, v.35, p.123-129, 1972.

ESTEFANEL, V. et al. Insolação e radiação solar em Santa Maria, RS: I - Estimativa da radiação solar global incidente a partir dos dados de insolação. Revista do Centro de Ciências Rurais. Santa Maria, v.20, n.3-4, p.203-218, 1990.

FYNN, R.P. et al. Evapotranspiration measurement and modeling for a potted chrysanthemum crop. Transactions of the ASAE, St. Joseph, v.36, n.6, p.1907-1913, 1993.

HELDWEIN, A.B. et al. Utilização do evaporímetro de Piche exposto a radiação solar para estimar a evapotranspiração máxima do pimentão em estufa plástica. Revista Brasileira de Agrometeorologia, Santa Maria, v.9, n.2, p.213-214, 2001.

HELDWEIN, A.B. et al. Modelos para a estimativa da evapotranspiração máxima da abóbora italiana em estufa plástica. Revista Brasileira de Agrometeorologia, Santa Maria, v.12, n.1, p.75-86, 2004.

JOLLIET, O.; BAILEY, B.J. The effect of climate on tomato transpiration in greenhouses: measurements and models comparison. Agricultural and Forest Meteorology, Amsterdam, v.58, p.43-62, 1992.

MARCELIS, L.F.M. Simulation of plant-water relations and photosynthesis of greenhouse crops. Scientia Horticulturae, Amsterdam, v.41, p.9-18, 1989.

MORENO, J.A. Clima do Rio Grande do Sul. Porto Alegre: Secretaria da Agricultura. 1961. 46p.

NERDERHOFF, E.M. et al. Leaf conductance and rate of crop transpiration of greenhouse grown sweet pepper (Capsicum annuum L.) as affected by carbon dioxide. Scientia Horticulturae, Amsterdam, v.52, p.283-301, 1992.

OKUYA, A.; OKUYA, T. The transpiration of greenhouse tomato plants in rock wool culture and its relationship to climate factors. Acta Horticulturae, Wageningen, v.230, p.307-311, 1988.

RIGHI, E.Z. Consumo hídrico do tomateiro (Lycopersicon esculentum Mill.) cultivado em estufa plástica e sua relação com variáveis meteorológicas em Santa Maria, RS. 2000. 83f. Dissertação (Mestrado em Física do Ambiente Agrícola) Escola Superior de Agricultura Luiz de Queiróz, Universidade de São Paulo. 
STANGHELLINI, C. Evapotranspiration in greenhouse with special reference to Mediterranean conditions. Acta Horticulturae, Wageningen, v.335, p.295-304, 1993.

VALANDRO, J. et al. Transpiração do tomateiro cultivado fora do solo em estufa plástica e sua relação com a radiação solar. In: CONGRESSO BRASILEIRO DE
AGROMETEOROLOGIA, 11., REUNIÃO LATINOAMERICANA DE AGROMETEOROLOGIA, 2., 1999, Florianópolis, SC. Anais... Florianópolis: Sociedade Brasileira de Agrometeorologia. 1999. 1 CD.

YANG, X. et al. The microclimate and transpiration of a greenhouse cucumber crop. American society of Agricultural Engineers, St. Joseph, v.32, n.6, p.2143-2150, 1989. 